\title{
The Prosody of Topicalization ${ }^{1}$
}

\author{
Caroline Féry
}

\begin{abstract}
Because of the elusive nature of pitch accents and prosodic phrasing, the role of prosody has been neglected too often in the description of the syntax-phonology interface. This paper shows that the syntactic structure of German sentences is shaped by the formation of prosodic phrases, and that many puzzles are solved if prosodic phrasing and accents are systematically considered in formal grammar. Some types of topicalization, like contrastive topicalization and split constituents, are motivated by the need to separate two accents which would be adjacent in an unmarked word order. The sentence has now two different intonation phrases, with the fronted constituent bearing an accent equal in strength to the preverbal focus one. The proposal is couched in an optimality theoretic framework, allowing direct interactions between prosody and syntax.
\end{abstract}

\section{Introduction}

In German, the language under consideration in this paper, topicalization is related to a special phonological structure. A topicalized constituent is located at the very beginning of a sentence where it has a prominent rising accent on its accented syllable and where it is separated from the rest of the sentence by a boundary tone, or even by a short break (see for instance Büring 1997 Jacobs 1997 and Féry 1993). In this paper 'topicalization' is understood as a syntactic and prosodic operation on constituents, and 'topic' as the pragmatic or semantic information structural content associated with topicalized constituents. From the syntactic perspective, the finite verb of a main clause is located in the second position of the sentence, and the prefield has to be filled. It is thus a natural consequence that a constituent in the prefield is not necessarily topical. Nominative arguments, dative arguments of passive and psych verbs, temporal adverbs, sentence level adverbs, etc. are often the first constituents of the sentence by virtue of being the 'highest' constituent of their clause (see below). The present paper focuses on the pre-field elements which are topical and which have been topicalized by a syntactic operation. It suggests that true topicalization has a prosodic origin. From the point of view of the prosody, the motor of topicalization is first the need to fulfill a constraint NoCLASH which prohibits adjacent accents, and second the need to realize a rising intonation on a constituent in order to express its topical character. This is why elements with a pragmatic topic land in the first position of the sentence, rather than somewhere else.

The next section introduces the theoretical framework of the paper. The optimalitytheoretic approach to the syntax-prosody interface leans on a proposal developed in Féry \& Samek-Lodovici (2006). Section 3 introduces different kinds of topics and topicalizations and shows that the syntactic structure of 'contrastive' topics, as opposed to 'stylistic fronting' or 'formal movement' (Fanselow 2002, Frey 2004) is reflected in the prosody. Section 4 discusses split constructions in which a noun is left-dislocated. In both contrastive topicalizations and split 
constructions, the need to separate two pitch accents corresponding to two discourse structural properties can be considered as the motivation for the syntactic construction.

\section{Theoretical framework}

Féry \& Samek-Lodovici (2006) propose an optimality-theoretic approach to the syntax-prosody interface (see also Prince and Smolensky 1993, McCarthy \& Prince 1993 for Optimality Theory and Truckenbrodt 1995, 1999, Selkirk 2000, Büring 2001, 2003b, Samek-Lodovici 2005 and Szendröi 2003 for OT approaches to the syntax-prosody interaction). The prosodic structure of English sentences is shaped by constraints pushing phrasal and sentential accents as far to the right in their prosodic domain as possible (1a-b), reproducing the effects of the Nuclear Stress Rule (Chomsky \& Halle 1968). The unique lexical head of a maximal projection is expected to be associated with a pitch accent, and as a result, to be the head of a prosodic domain (2). The typical head-argument stress pattern, with a pitch accent on the argument but none on the head, is a consequence of this constraint, see Gussenhoven (1992), Selkirk (1984), Cinque (1999), Büring (2001) and others for different proposals to this effect. In (3), constraints are formulated which restrict the number of prosodic constituents to a minimum. ${ }^{2}$

(1) a. HP: Align the right boundary of every P-phrase with its head.

b. HI: Align the right boundary of every I-phrase with its head.

(2) STRESSXP: Each lexically headed XP must contain (maximally) one phrasal stress. ('Phrasal stress' refers to the head of a P-phrase.)

(3) a. *P-PHRASE: No phonological phrase.

b. *I-PHRASE: No Intonation phrase

The effects of these constraints on the prosodic phrasing and placement of accents are comparable in German and in English, and they are illustrated in Table 1 with the German example (4), understood as a whole-focused, all-new sentence.

(4) Sie hat heute morgen Rosen gekauft. she has today morning roses bought 
Table 1: $\quad[\text { Sie hat heute morgen Rosen gekauft }]_{\mathrm{F}}$

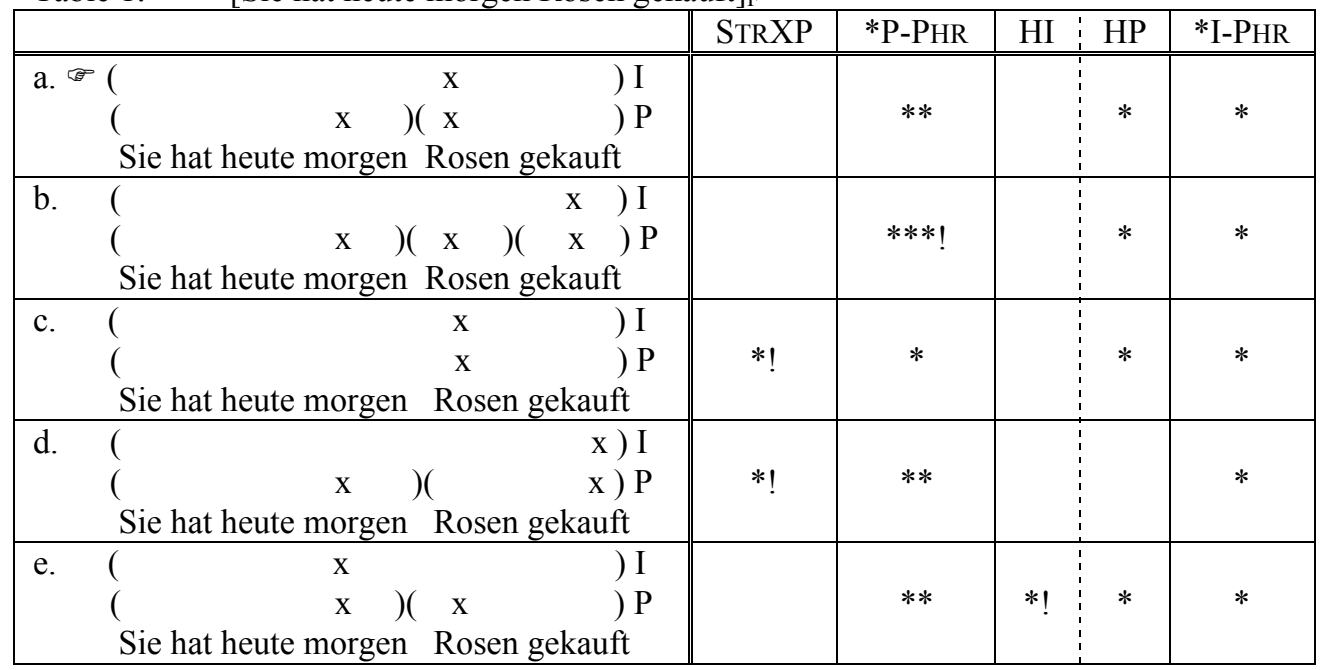

Candidate (a) in Table 1, with two P-phrases and one I-phrase, fulfills the constraints best. This candidate violates HP since the head of the prosodic constituent formed on the direct object plus the verb is not rightmost but this violation is forced by the combined effect of STRESSXP and *PPhrase. StressXP requires that lexical heads are heads of prosodic constituents, and *PPHRASE restricts the number of P-phrases to a minimum. It guarantees that no phrase is formed to the sole effect of fulfilling HP. HP, as well as HI, only controls the location of the accent in demanding that it is as far to the right in the domain under consideration as possible. The accent on Rosen is enough to fulfill STRESSXP with respect to both the NP Rosen and the VP Rosen gekauft. An additional accent on the verb, as in candidate (b), implies one more violation of *PPhrASE. The ranking between STRESSXP and *P-PHRASE is crucial, as can be seen from candidate (c). This candidate has only one phrase and thus does better on *P-PHRASE than candidate (a). But crucially, it violates STRESSXP whereas candidate (a) does not: heute morgen, a syntactic maximal projection, has no accent. Candidate (d) also fulfills HP better than (a) and (b), but is eliminated by high-ranking STRESS-XP, because not all syntactic phrases have a corresponding prosodic head: the NP Rosen has none. And finally candidate (e) entails a gratuitous violation of HI. In short, this tableau illustrates that STRESSXP must be higher-ranking than the other constraints, and that *P-PHRASE must be higher ranking than HP and HI, but lower ranking than STRESSXP. The ranking STRESSXP $>>*$ P-PHRASE $>>$ HI, HP $>>$ *I-PHRASE is thus partly established. The constraint *I-PHRASE is relatively low-ranking. It should be clear that adding an IP in (4) does not ameliorate the optimal candidate. There is no evidence that HP and HI have to be ranked relatively to each other. These two constraints do not interact. The remaining of the ranking will be established below, in further tableaux.

The approach developed in Féry \& Samek-Lodovici (2006) relates pitch accents directly to the discourse structure of English utterances and differs in this respect from Selkirk's (1995) model and also from Schwarzschild's (1999) improvements to Selkirk in giving up projections of F-marks. Selkirk requires the association of pitch accents with F-marks which are allowed to project higher in the syntactic tree according to two projection rules. First, F-marking of the head of a phrase licenses the F-marking of the phrase, and second, F-marking of an internal argument 
of a head licenses the F-marking of the head. These rules, though very influential, have been shown to be too restrictive by Schwarzschild (1999) and Büring (1997, 2003b), who demonstrate that if heads and internal arguments have to be unstressed by virtue of being discourse given, a specifier, adjunct or any other element can be the accent bearer of a larger focus domain. Selkirk's rules, however, prohibit the projection of an accent from such constituents. Schwarzschild proposes replacing the projection rules by free assignment of F-marks. He also limits their effect by positing a series of constraints. One of these is GIVENness (in (5a)), positing that a constituent that is not F-marked is given. As a consequence, all new constituents are F-marked, and constituents which are F-marked can be new or given. Another constraint introduced by Schwarzschild is AvOIDF, formulated in (5b), which limits the occurrence of Fmarks.

(5) a. GiVENNESS: A constituent that is not F-marked is given.

b. AvOIDF: Do not F-Mark.

In Schwarzschild's example (6), the VP is not given since it is not mentioned in the previous discourse, nor is it entailed by the previous discourse and crucially, neither the verb praised nor the object her brother are given (see the precise definition of givenness in Schwarzschild 1999). The location of the pitch accent is decided by an extra constraint which posits that a head is less prominent than its internal argument(s). In (7), both praised and him are given by virtue of being introduced in the context in curly brackets, but the fact that she praised John is not given, so that the VP is not given. Constraint (5a) cannot choose between a candidate in which the whole VP is F-marked, as in (7b), and one in which only him is F-marked, as in (7a). The choice between the two is decided by AVOIDF, which chooses (7a) because it has fewer F-markings than (7b). ${ }^{3}$

(6) \{What did Mary do?\}

A: She $\left[\text { praised }_{\mathrm{F}}[\text { her BROTHER }]_{\mathrm{F}}\right]_{\mathrm{F}}$

(7) \{Who did John's mother praise?\}

a. $\quad$ She praised $[\mathrm{HIM}]_{\mathrm{F}}$

b. She $\left[[\text { PRAISED }]_{\mathrm{F}} \text { him }\right]_{\mathrm{F}}$

Problematic for both Selkirk's and Schwarzschild's approaches, as well as others like Büring (2003b), are examples like (9) from Rooth (1992), (10) from Neeleman \& Szendroi (2004) and (11) from Féry \& Hartmann (2005), in which main accents are not rightmost in their respective focus domains, even if the whole sentence is discourse new. In Féry \& Samek-Lodovici (2006), constraints (5) are replaced by STRESSFocus and DESTRESSGIVEN in (8), which outline the relationship between discourse structure and accents in a direct way.

(8) a. STRESSFocUs (SF): A focused phrase has the highest prosodic prominence in its focus domain.

b. DestressGiven (DG): A given phrase is prosodically non-prominent.

These constraints interact with the prosodic constraints in order to determine the placement of accents. In the sentences under consideration, the location of main stress is conditioned by nested foci in which a focus, contrastive or not, is embedded into a larger one. In (9) for instance, the 
NP an American farmer is all new, and HP, as well as STRESSXP, conspire to locate the stress rightmost, thus on farmer. But the contrast between American and Canadian triggers a second focus on American, and because of the adjacency of the adjective and the noun, only one of these elements is accented. The realization of two adjacent accents in a p-phrase is strongly dispreferred both in English and in German. The contrast between the adjectives must be realized, more so than the default accent on farmer, and as a result, the least violation is elicited by a candidate with a unique accent on the adjective. The constraints operate similarly in examples (9), (10) and (11), in which one instance of focus is nested into a larger one, and attracts the accent because of prosodic adjacency.

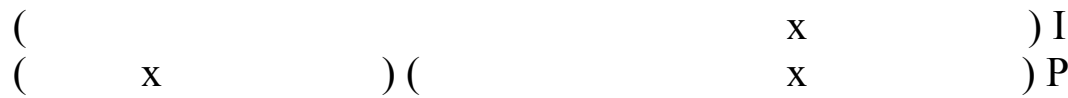

[an AMERICANF farmer was talking to a CANADIAN farmer $_{\mathrm{F}}$

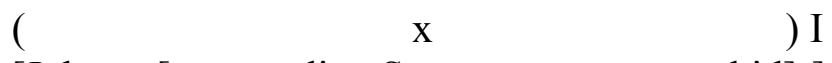

[Johnny [was reading SUPERMAN ${ }_{\mathrm{F}}$ to some kid $\left.]_{\mathrm{F}}\right]_{\mathrm{F}}$

(11)

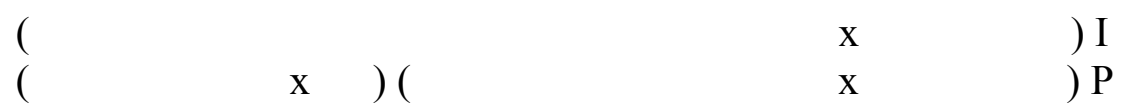

[Ramon likes CUBANF and Malte prefers ARGENTINIAN music $_{\mathrm{F}}$

Féry \& Samek-Lodovici (2006) show that the addition of a constraint STRESsFocus is inescapably necessary to account for embedded foci. Because of this constraint, the focus elicited by the contrast between the adjectives must be realized by a higher prominence than anything else in the NP, as illustrated in Table 2.

Table 2: $\quad\left[\right.$ An American ${ }_{\mathrm{F}}$ farmer was talking to a Canadian farmer $_{\mathrm{F}}$

\begin{tabular}{|c|c|c|c|c|}
\hline & & SF & STRESSXP & $\mathrm{HP}$ \\
\hline$\overline{~ a .}$ & 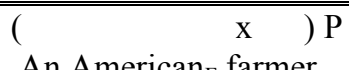 & $* 1$ & & \\
\hline b. & $\begin{array}{l}\text { An American } \text { F farmer }^{\mathrm{x}} \text { ) P } \\
\left(\begin{array}{c}\mathrm{x} \\
\text { An }_{\text {American }} \text { farmer }\end{array}\right.\end{array}$ & & & $*$ \\
\hline
\end{tabular}

We now have extended the existing constraint ranking: SF $>>$ STRESSXP $>>$ *P-PHRASE $>>$ HI $>>$ HP $>$ * *-PHRASE. In the next section, STRESSTOPIC (ST) will be introduced in order to apply this framework to sentences with topic constructions.

\section{Topic and topicalization}

\subsection{Topic}

Topic as a pragmatic category has been attributed a number of roles in the literature, like familiarity, aboutness, contrast, implication, partiality, all of which are well-attested and fulfill different aims in sentences. A familiarity topic in the sense of Givón (1990) and Lambrecht (1994) is a discourse-linked constituent, often (but not always) referred to by means of a 
pronoun, an anaphoric element or a deaccented constituent (see Prince 1981 and Gundel 1996 for relevant examples). Such a familiarity topic is given or inferable, or salient, and it tends to occupy the pre-field in German as the consequence of Formal Movement (see section 3.2).

This paper concentrates on contrastive topics. 'Contrastive' is used as a cover term for different pragmatic categories, sharing the fact that they elicit a set of alternatives, as shown by Büring (1997). Aboutness and frame-setting topics are forming a subclass of mildly contrastive topics which can be classified as discourse-setting. Aboutness, or shift topics specifies 'what the sentence is about' (Reinhardt 1981). This use of a topic can be understood as contrastive if the sentence could have been about something else. The example in (12), adapted from Jacobs (2001), illustrates this first meaning of topic. The speaker says about her mother that her health is fine, implying at the same time that there are other aspects which could be addressed as well, like her intellectual, marital, financial or psychic state.

(12) Gesundheitlich geht es meiner Mutter gut.

'As far as health is concerned, my mother is well-off.'

Frame-setting may be a variant of aboutness. It sets the sentence in a locational or temporal frame. Some examples are given in (13).

(13) On Saturday, we usually go to the market and shop for the whole week.

In Cannes, older couples are spending several hours a day on the Croisette.

Implicational and partial topics are strongly contrastive. An implicational topic is intrinsically contrastive. Büring's (1997) example is reproduced in (14). A realization of this sentence with a rising accent on the subject and a falling accent on the negation keine implies that somebody else's wife might have kissed strangers. Meine Frau is contrasted with X's Frau.

(14) MEINE/ Frau hat KEINE $\backslash$ fremden Männer geküsst.

'My wife hasn't kissed strangers.'

Partial topics are semantically and pragmatically elements of alternative sets (or posets in Prince's terms). Büring (2003a) claims that an English contrastive topic is always realized by a fall-rise accent (B accent in Jackendoff 1972 and Steedman 2000) and that the term 'contrastive topics' that he uses to refer to these elements is in fact referring to Accent B. In the same paper, Büring takes up Roberts' (1996) proposal that contrastive topics are reflecting a complex strategy of questions. In this perspective, the typical contrastive topic is a partial topic. This is best illustrated with Jackendoff's (1972) famous example in (15) and (16).

(15) a. Who ate what?

b. What about the beans? Who ate them?

c. What about Fred? What did he eat?

d. Fred ate the beans.

The strategy of questions used in dialogues using elements like those of (15) is illustrated in (16).

(16) a. Who ate what? 

b. What did Fred eat?

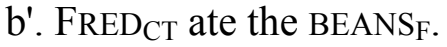
c. What did Mary eat?
$c^{\prime}$. MARY $_{\mathrm{CT}}$ ate the EGGPLANTF.
etc.

The same question (16a) can be submitted to a strategy in which the next move after (16a) is to ask who ate some specific vegetable, as illustrated in (15c). The difference between the strategy illustrated in (16) and the latter one is that now the vegetables are contrastive topics, and no longer the persons who ate them.

Partial topics thus are ideal representants of topichood, but the other types of topics can be interpreted along the same lines, i.e. as being elements of a set of alternatives of the same class, or smaller. Even if aboutness and frame-setting topics, implicational and partial topics have different environments and different pragmatic implications, their common property is that they choose out of a set of inferable alternatives which element the sentence is about. It is this 'contrastive' property which is meant in the examples below.

\subsection{Topicalization}

German is a V2-language, which means that a pre-verbal position in a main clause is obligatorily occupied (see Thiersch 1978, and many others after him). This position is traditionally called the prefield (Vorfeld), and can be filled by a variety of constituents. According to Frey (2004), there are three different types of prefields in German. First, constituents which have been leftdislocated by true A-bar-movement, an operation which moves any constituent from the middle field (Mittelfeld), preserving whatever pragmatic property the constituent has acquired in this position. This operation always results in a contrastive interpretation. Second, a topicalized constituent can be first moved to the left of the subject, into a position occupied by topicalized constituents in the middle field, and only in a second step, this constituent is moved to the sentence-initial position (see also Müller \& Sternefeld 1993, Grewendorf \& Sabel 1994 and Haider \& Rosengren 1998 for the view that arguments can be placed into a pre-subject position by scrambling). This topicalization is triggered by information structure and affects (maximal projections of) any category. It occurs both in root and in embedded clauses, and there must not be a resumptive pronoun related to it in the main clause. It is prosodically separated from the main clause by a prosodic boundary.

Elements arrive at their prefield surface position by means of a process called 'Formal Movement' in Frey (2004) which moves whatever is the highest element in the local middle field to the prefield in a pragmatically vacuous manner. Elements moved by formal movement only do not get a contrastive interpretation. In the unmarked situation, it is the subject of the sentence, but it can also be dative arguments of unaccusative and passive constructions, whichever element is the structurally highest phrase in IP (see also Lenerz 1977 and Müller 2003 for examples). For these elements, it is also the case that the highest position is their basis position. Prosodically, no particular emphasis is expected in this case. The difference between this operation and the preceding ones is that there is no movement due to pragmatic reasons in the middle field prior to the Formal Movement. A-bar topicalization may be related to filling the SpecCP, whereas the Formal Movement involves filling the SpecFinP (in Frey's account) or SpecIP. The difference is illustrated in (17) and (18).

Frey also recognizes a third possibility for filling the prefield, corresponding to a base generation of some constituents which are not licensed clause-internally. Adverbials which relate 
to the discourse may be of this type, an example of which is given in (19). Some temporal adverbials also appear clause-initially without having any special pragmatic meaning.

(17) A-bar topicalization

a. [CP das Paket 2 hat 1 [IP Karl t $\mathrm{t}_{-}\left[\mathrm{VP} \mathrm{t}_{2}\right.$ weggebracht $\left.\left.\mathrm{t}_{1}\right]\right]$

the package has Karl taken.away

'Karl has taken the package away.'

b. Mit dem Hammer hat Otto das Fenster eingeschlagen

with the hammer has Otto the window smashed

'Otto smashed the window with the hammer.'

(18) Formal Movement

a. [IP Karl hat 1 [vp das Paket weggebracht t 1 ]]

Karl has the package taken.away

b. Einem Mitbewohner wurde die Geldbörse entwendet

a-DAT flatmate was the purse stolen

'A purse was stolen from a flatmate.'

(19) Base generation

Ein Glück habe ich den Regenschirm dabei

a luck have I the umbrella with.me

'Fortunately, I have an umbrella with me.'

Frey claims that his proposal explains why constituents situated in the local prefield may be noncontrastive, whereas topicalized constituents moved over long distances are necessarily contrastive, and also why narrowly focused elements positioned in the prefield require other contexts than those which remain in situ.

Fanselow (2004) also distinguishes between the three forms of topicalization, but he proposes a unified analysis for A-bar movement and Formal Movement, the latter process he calls Stylistic Fronting. Both movements are explained in terms of feature checking. In A-bar movement an operator feature $[+\mathrm{g}]$ attracts a constituent which possesses $[+\mathrm{g}]$ as well. This feature may be an information structural feature like [+top] or [+foc]. In this case, a structurally higher category may be skipped for movement if it does not carry the matching feature, in violation of the Minimal Link Condition. In Stylistic Fronting, the attracting feature is an ordinary EPP-feature and the element closest to SpecCP is attracted.

Whatever the best syntactic analysis of topicalization turns out to be, the difference between A-bar-movement and pragmatically vacuous formal movement, or between EPP and information structural features is a useful distinction, which is reflected in the phonetic implementation. It is proposed here that the distinction should be implemented in the prosodic representation. Compared to its unmarked position in a clause, A-bar topicalization has the main effect of separating the topicalized constituent into a separate I-phrase. Compare (20). ${ }^{5}$

(20) a. $\quad\left[[\text { Mein Bruder }]_{\mathrm{P}}[\text { hat seiner Tochter }]_{\mathrm{P}}[\text { neue SCHUHE gekauft }]_{\mathrm{P}}\right]_{\mathrm{I}}$ My brother has his-DAT daughter new shoes bought

'My brother has bought new shoes for his daughter.'

b. $\left[\left[[\text { Seiner TOCHTER }]_{\mathrm{P}}\right]_{\mathrm{I}}\left[[\text { hat mein Bruder }]_{\mathrm{P}}[\text { neue SCHUHE gekauft }]_{\mathrm{P}}\right]_{\mathrm{I}}\right.$ 


\section{His daughter has my brother new shoes bought}

In (20a), the sentence is in its unmarked word order, with the subject in the prefield. Subject and internal arguments each form a separate P-phrase, and the whole sentence is included into one Iphrase (I). This sentence is intended to be wide-focused. Stylistic Fronting has applied and as a result, the subject has been moved to the prefield in a pragmatically vacuous manner because it was the highest element in the local middle field. The prosodic constraints can not help but select the candidate with the highest prominence on Schuhe as the optimal candidate, which is candidate (a) in Table 3. For reasons of space, the tableau only displays the verb's objects (internal arguments), and ignores the subject (external argument, see Table 1 instead). If both direct and indirect objects are in the same I-phrase, the phrase formed on the pre-participial argument plus the verb bears the sentential stress. The addition of prominence on the indirect object in Table 3 leads to an unavoidable violation of HI, as illustrated by candidate (c).Candidate (b) is suboptimal because it entails a violation of HI, which is absent in candidate (a). Candidate (d), with two I-phrases, loses the competition with (a) just because it contains two violations of *I-PHRASE.

Table 3: $\quad$ [seiner Tochter neue Schuhe gekauft $]_{\mathrm{F}}$

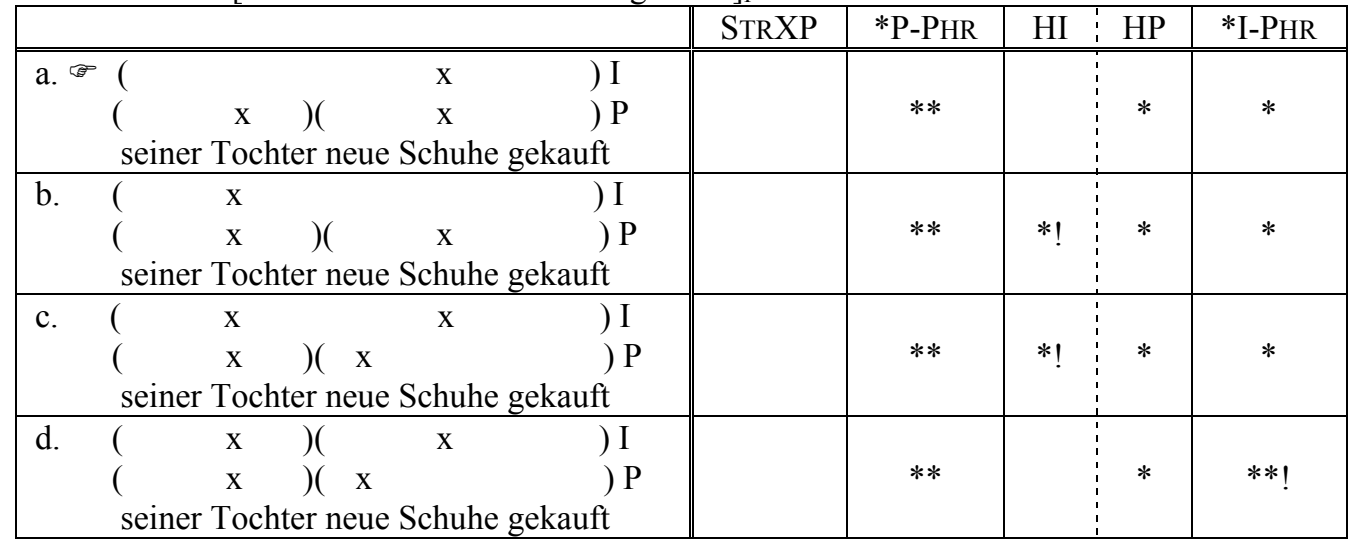

In (20b), the indirect object has been topicalized. In the intended interpretation, this object is a contrastive topic and the remainder of the sentence contains a focus, or is whole-focussed. For this reason, two main stresses are needed, one of them triggered by STRESSFOCUS (SF), which was formulated in (18a) and the other one by STRESSTOPIC (ST), formulated in (21). In the same way that SF requires a focus to be the most prominent element of its focus domain, ST requires a topic to be the most prominent element of its topic domain (for a definition of focus domain see Féry \& Samek-Lodovici 2006 who lean on a proposal by Truckenbrodt 1995).

(21) StRESS-TOPIC (ST): A topic phrase has the highest prosodic prominence in its topic domain.

Since in (20b) two internal arguments require a prominent head, two IPs are formed, which can have equal prominence, as illustrated by candidate (a) in Table 4 . The dative object is a contrastive topic, and ST requires it to be the most prominent element of its domain. In order to satisfy ST, the topic is separated from the rest of the clause by a stronger phrase boundary, an intonation phrase boundary. Thus, topicalization goes together with the creation of a new prosodic domain, and allows the topicalized constituent to be as prominent as the pre-verbal 
direct object. Candidate (a) is better than candidate (b) because it fulfills both ST and HI: both IPs have an equally strong head. Candidate (b) fulfills HI as well, but violates ST by virtue of integrating the topical accent in the same IP as the focal one. Candidate (c) shows why an IP must be created on the topicalized constituent: it is not possible to attribute equal prominence to two P-phrases in a single IP without violating HP. The ranking HI $>$ * * -Phrase is motivated in this tableau. And finally, candidate (d) illustrates why topicalization implies fronting to the prefield. If the indirect object remains in the middle field (and the subject is fronted by Formal Movement as in (20a)), three I-phrases are created, one more than in candidate a. This, however is penalized by *I-Phrase.

In the syntactic approach sketched out above, the subject in candidate (a) remains in its canonical position, which is the first position of the middle field. As a consequence, it does not have to bear any special pragmatic interpretation, either when it is in the prefield or when it has been fronted by formal movement, an assumption which seems to be borne out, and which comes as a natural result in the OT analysis proposed here.

Table 4: $\quad[\text { seiner Tochter }]_{\mathrm{T}}[\text { hat mein Bruder neue Schuhe gekauft }]_{\mathrm{F}}$

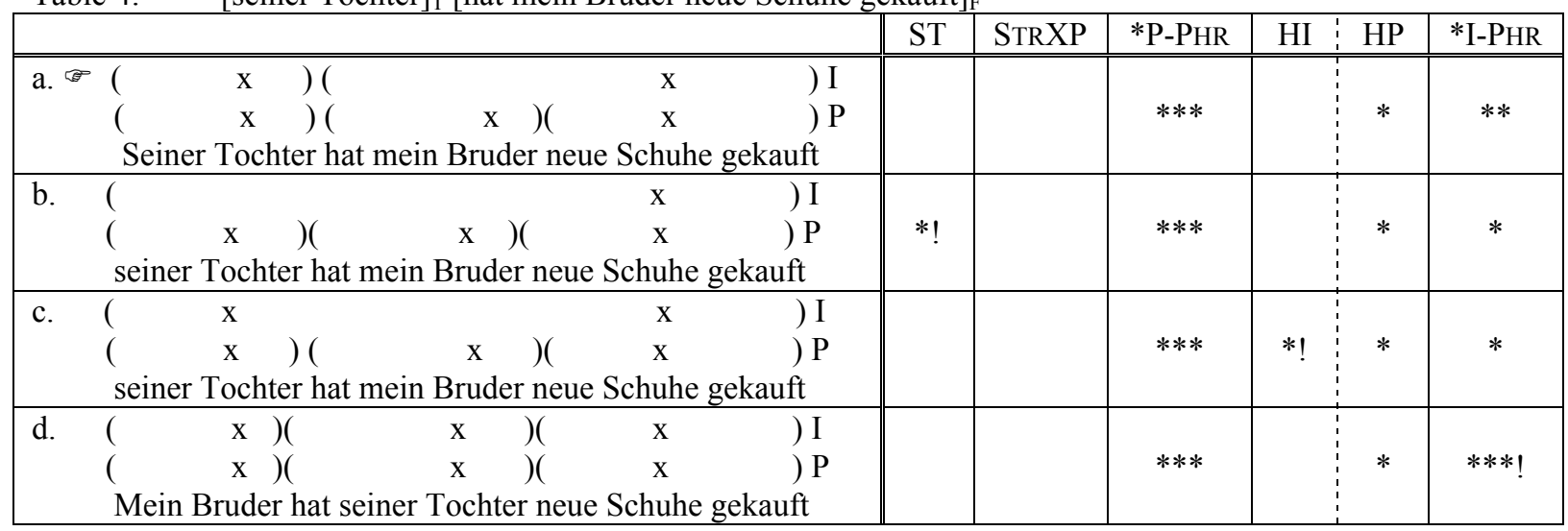

The same prosodic structure, with two IPs, can be realized with the unmarked syntactic structure, as shown in (22), but it is in several respects less well-formed. First, the initial prosodic domain does not correspond to a syntactic phrase, and second, the two most prominent accents of the sentence are adjacent and violate as a result the constraint NoCLASH, formulated in (23), a violable constraint (Hayes 1995, Elenbaas \& Kager 1999).

\section{$[\text { Mein Bruder hat seiner TOCHTER }]_{\mathrm{IP}}[\text { neue SCHUHE gekauft }]_{\mathrm{IP}}$} My brother has his-DAT daughter new shoes bought

(23) NoCLASH: Equally strong accents are not adjacent.

The result of this section can be summed up as follows: topicalization of a maximal projection is triggered by the need to allow two constituents to be equally prominent. If two adjacent verbal arguments both require main accents, it is better to move one of them to the initial position of the sentence. Prosodically, it then forms a separate Intonation Phrase which can get as much prominence as the preverbal argument. Leaving both arguments in their canonical position leads to violation of the prosodic constraints. In the next section, it is shown that the same motivation, namely avoidance of stress clash and better prosodic shape, is also at play in discontinuous or split constructions, in which non-maximal projections are involved. 


\section{$4 \quad$ Split constructions}

In discontinuous (or split) constructions, a nominal phrase is divided into two segments, separated by independent material. In (24a), the NP rote Rosen is in the middle field in its canonical order, with the adjective preceding the noun. In (24b), the noun Rosen is in the prefield, and thus precedes the adjective. The adjective rote is in the middle field, as in the canonical order, but now it is adjacent to the verb. Again an additional incidental change concerns the location of the subject, which is before the finite verb in (24a) and after it in (24b). As explained in the preceding section in relation with the discussion of (20b), both locations are unmarked.
a. Maria hat rote Rosen gekauft. Mary has red roses bought
b. Rosen hat Maria rote gekauft. roses has Mary red bought

This construction has been intensively studied from a syntactic perspective and has been alternatively analyzed in terms of movement or in terms of base-generation (see De Kuthy 2002 for a summary of the arguments for and against these options, and also van Hoof 2004 for an overview of the constructions in several languages). In the movement or remnant movement approach, the noun is moved to the front of the sentence, and the adjective remains in situ (see for instance van Riemsdijk 1989 and Müller 1998). In the base-generation or reanalysis model (see Fanselow 1987), the noun is generated in the prefield. An alternative explanation is the copy-and-deletion approach (Fanselow \& Cavar 2002) in which the whole NP generated in the middle field is copied in the prefield, and the unrealized material is deleted in both positions. It is important to observe that there are a number of discrepancies between the continuous and the discontinuous versions of the NP, the most obvious ones being number incompatibility, and regeneration of a preposition (see van Riemsdijk 1989 for German), facts which disfavor a movement approach. From a typological perspective, this kind of 'inverted' split construction is only possible in languages which permit noun-dependents to be nominals by themselves, a second factor strongly speaking for base-generation as the most plausible analysis.

Fanselow \& Cavar (2002), as well as De Kuthy (2002) and Féry \& Paslawska (2005) for Ukrainian, consider not only the syntactic facts but also the discourse structural motivation for split constructions. They find a motivation for the NPs' discontinuity in their information structural properties. In most cases, the preposed element is a topic and the element in situ is a focus. Thus, (24b) could be typically uttered in a situation in which roses have been previously introduced into the discourse. In the sentence under consideration, they are mentioned again and contrasted with other flowers. The speaker adds the new or otherwise prominent information that the roses Mary bought are red (rather than of another color).

From the perspective of the prosody, the set of constraints introduced until now lead to a structure in which the word Rosen in (24a) invariably bears main prominence. This is illustrated in Table 5. 
Table 5:

[Maria hat rote Rosen gekauft $]_{\mathrm{F}}$

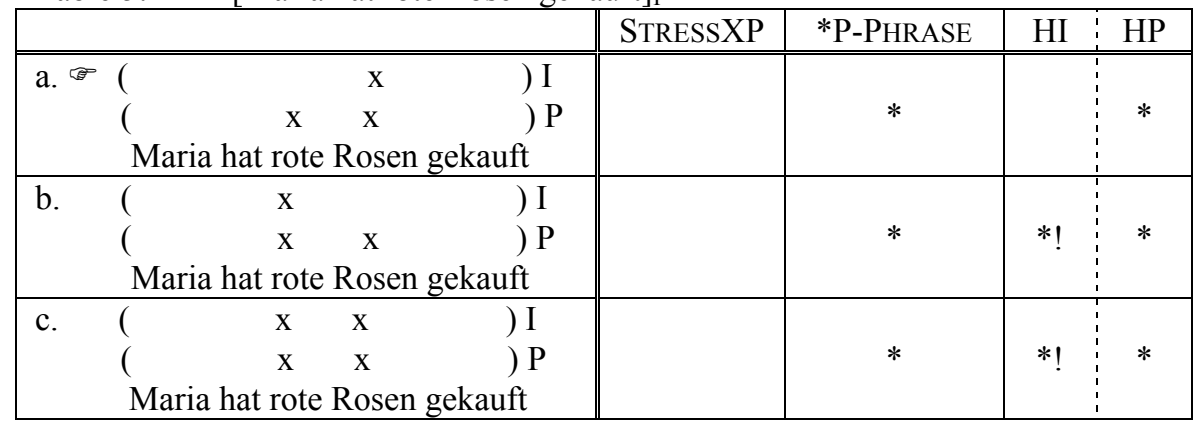

Table 5 contains a simplification since the NP rote Rosen contains two lexical heads, an adjective and a noun, and STRESSXP requires both of them to project a phrasal accent. The whole NP is finally accented, and is analyzed as a recursive P-phrase, as shown in (25). The adjective and the noun are integrated into a single P-phrase on rhythmical grounds (Nespor \& Vogel 1986, Selkirk 1984, Ghini 1993). In the following, the lower P-phrase structure is no longer considered.

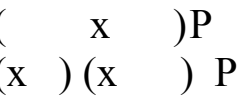

(25)

The discontinuity of an adjective (or quantifier, numeral and the like) and its head noun finds a double motivation. First, as illustrated in the preceding section with maximal projections, the need to provide both elements with equal prominence triggers the formation of two phrases, topicalization being the most obvious solution. Indeed, it allows a structure which fulfills NoClASH by keeping the two prosodic heads as far apart as possible. In split constructions, the prosodic phrases are not adjacent, as has been demonstrated for contrastive topicalization in the preceding section. Second, the sentence initial position is preferably associated with a rising bitonal tone for topic, and the preverbal one with a falling accent for focus (see Büring 1997). When adjective and noun are adjacent, assigning two accents inevitably leads to a rising accent on the adjective and a falling one on the noun, the reverse of what is found in a split construction. In Table 6, *I-PHRASE is left out for reason of space. A candidate with only one Iphrase, like (b) and (c) is eliminated through the effect of higher-ranking constraints.

Table 6: $\quad[\text { Rosen }]_{\mathrm{T}}$ hat sie $[\text { rote }]_{\mathrm{F}}$ gekauft

\begin{tabular}{|c|c|c|c|c|c|c|}
\hline & SF & ST & STRESSXP & *P-PHRASE & $\mathrm{HI}$ & HP \\
\hline 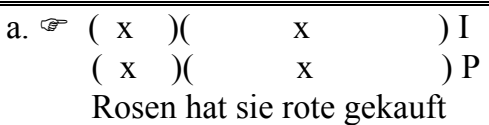 & & & & $* *$ & & $*$ \\
\hline $\begin{array}{lll}\text { b. } & (\mathrm{x} & \\
(\mathrm{x})(\mathrm{I} & \mathrm{I} \\
& \text { Rosen hat sie rote gekauft }\end{array}$ & *! & & & $* *$ & $*$ & $*$ \\
\hline $\begin{array}{llll}\text { c. } & \left(\begin{array}{ll}( & \mathrm{x}\end{array}\right) \mathrm{I} \\
& (\mathrm{x})(\mathrm{x}) \\
\text { Rosen hat sie rote gekauft }\end{array}$ & & $* !$ & & $* *$ & & $*$ \\
\hline
\end{tabular}

Note that an interpretation of the preposed element as a topic is facultative. It can also be a focus, the only restriction being that the two parts of a split construction cannot be elements of one and 
the same focus. The fronted part can also be the only focus of the sentence, in which case the remaining of the sentence is backgrounded, and deaccented. If both elements of a split construction bear structural information, an asymmetrical information structure seems to be obligatory in split constructions. A dialogue like (26) is not well-formed, if B's answer is intended to be exhaustive. In a well-formed answer to (26A), adjective and noun, which form together a narrow focus, are adjacent, as shown in the three well-formed options in (26C). Only the noun carries main stress.

(26) A: Was hat sie gekauft? 'What has she bought?'

B: \#ROSEN hat sie ROTE gekauft.

C: Sie hat rote RosEn gekauft./ Rote RosEn hat sie gekauft./ Rote RosEN.

Similarly, elements of split constructions cannot be parts of a single topic. This is illustrated in (27). In (27B) Rote Rosen and weiße Nelken are topics by virtue of being subsets of a given superset, and the verbs are the foci of the answer. Splitting the noun and the adjective induces a focus on the noun or on the adjective, which is not intended by the context (27A). A well-formed answer is provided in $(27 \mathrm{C})$ : the flowers and their color are topicalized and the participles are the foci of their clauses.

(27) A: Was hat sie mit roten Rosen und weißen Nelken getan?

'What has she done with red roses and white carnations?'

B. \#ROSEN hat sie ROTE GESCHNITTEN Und NELKEN hat sie WEIßE GEPFLÜCKT. roses has she red cut and carnations has she white picked.

C. ROTE ROSEN hat sie GESCHNITTEN und WEIßE NELKEN GEPFLÜCKT. red roses has she cut and white carnations picked.

Next, consider (28). In this example, both parts of the split construction (28B) are in focus, but crucially they are foci of two different wh-questions.

(28) A: Wieviele von welchen Blumen hat sie gekauft? How.many of which flowers has she bought?

B: ROSEN hat sie ZWÖLF und NELKEN (hat sie) ZWANZIG gekauft. roses has she twelve and carnations has she twenty bought.

C: Sie hat ZWÖLF ROSEN und ZWANZIG NELKEN gekauft. 'She has bought twelve roses and twenty carnations.'

D: *ZWÖLF hat sie ROSEN und ZWANZIG hat sie NELKEN gekauft.

'She has bought twelve roses and twenty carnations.'

A different and equally plausible analysis in (28B) involves a topic on the noun and a focus on the numeral. In this reading, Rosen and Nelken are members of a closed, contextually given set, and number of bought flowers is being questioned. In multiple questions there seems to be a strong tendency for one of the wh-words to be D-linked and act as a sorting key for the answer. ${ }^{6}$

In fact, both answers (28B and C) seem to be equally well-formed: violation of stress clash is as good an option as a split construction, (see $28 \mathrm{C}$ and also $28 \mathrm{~B}$ when the auxiliary hat and the pronoun sie are elided). In (28B), the nouns have preferably a rising accent and the adjectives a falling one, and the preferred analysis is one involving a topic and a focus. In (28C), both the 
numerals and the flowers are preferably analyzed as foci. There is no need to reverse the order of the adjective and the noun and the unmarked word order with the adjective preceding the noun is chosen, since there is no preference for a certain type of pitch accent on one of the two stressed words. (28D) is syntactically not well-formed, but, from the point of view of the information structure, it should be as good as (28B). As an answer to a question like Welche Blumen hat sie gekauft und wieviele? 'Which flowers did she buy, and how many?', (28B and C) are equally well-formed, whereas (28D) is again rather marked.

The next example, in (29), illustrates a sentence which contains different elements of the constructions that we have examined so far.

(29) Das gute Essen hat Maria immer gemocht, aber FISCH konnte sie noch NIE leiden The good food has Maria always liked but fish could she yet never bear 'Maria has always liked good food, but she always hated fish'

The proposal assumed in this paper enhances the prosodic side of such constructions, which is a direct consequence of avoiding stress clash and the need to realize two accents with equal prominence. Both nie and Fisch are accented by virtue of bearing individual pragmatic features, even in a context in which the whole sentence is focused. The structure of the preceding clause is such that two different points of information are required, the first being of the kind of food under debate and the second being Maria's taste. In addition to being part of the focus, Fisch can be interpreted as a topic and topics are better realized with rising accents. It is a topic by virtue of being inferable from good food (see Reinhart 1981 among others for the topic status of inferable items). The adverb nie has narrow focus, in addition to being part of the focus of the whole sentence. It is thus better with a falling accent. The information structure of a sentence like (29) is shown in (30). ${ }^{7}$

$$
\begin{aligned}
& {\left[[\text { FISCH }]_{\mathrm{T}}\left[\text { konnte sie noch }[\mathrm{NIE}]_{\mathrm{F}} \text { leiden }\right]_{\mathrm{F}}\right]_{\mathrm{F}}} \\
& \text { fish could she yet never bear }
\end{aligned}
$$

Table 7 shows how the constraints elicit candidate (a) as the optimal candidate. The optimal candidate (a) separates the topic and the focus in two different I-phrases. Nie is an embedded focus, and as such carries the prominence of the whole focused sentence instead of the verb leiden, which is, everything being equal, the rightmost stressable word (see Féry \& SamekLodovici 2006 and section 2). All the other candidates violate either SF or ST, and are thus eliminated from the outset. Candidate (b) is like candidate (a) except for the fact that it has an additional P-phrase on the final verb. It fulfills Stress XP and HP better than candidate (a) but nie is not the most prominent constituent in its domain, and thus it violates SF. Observe that preserving the prosodic structure of candidate (b), but moving the main accent to nie does not solve the problem, because at the level of the P-phrase, nie is not more prominent than leiden, and SF requires it to be at the level of the P-phrase as well. Candidate (c) does not attribute enough prominence to the topic, and candidate (d) violates SF because nie is not the most prominent item in its domain. In view of the focus of the whole sentence, the accent on Fisch is enough, but the prominence on nie is lacking. 
Table 7: $\quad\left[[\text { Fisch }]_{\mathrm{T}} \text { konnte sie noch }[\text { nie }]_{\mathrm{F}} \text { leiden }\right]_{\mathrm{F}}$

\begin{tabular}{|c|c|c|c|c|c|c|}
\hline & SF & ST & STRESSXP & $\mathrm{HI}$ & $\mathrm{HP}$ & *P-PHRASE \\
\hline 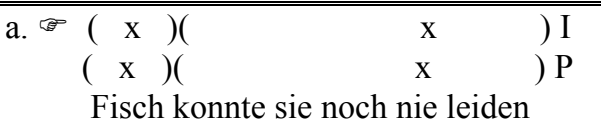 & & & $*$ & & $*$ & $* *$ \\
\hline 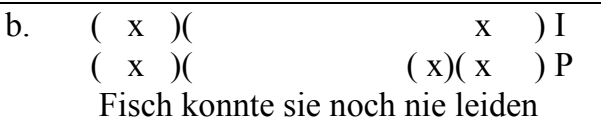 & $* !$ & & & & & $* *$ \\
\hline 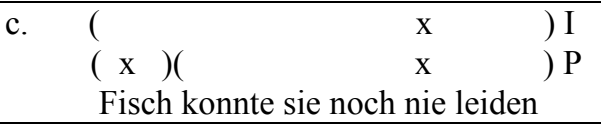 & & $* !$ & $*$ & & $*$ & $* *$ \\
\hline 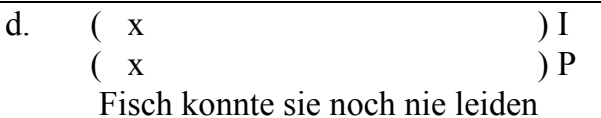 & $* !$ & & $*$ & $*$ & $*$ & $* *$ \\
\hline
\end{tabular}

To sum up this section, contrast, aboutness and topicality are properties associated with rising tones, and are usually found sentence initially. Splitting of constituents is induced by the need to realize two different discourse structure properties on the two elements, multiple foci and topic plus focus being the most obvious options.

\section{Conclusion}

Two constructions have been examined in the paper. First, contrastive topicalization, and second, split constructions. It has been shown that in both cases, prosody plays an important role for the motivation of these constructions, since it has the effect of changing the linear ordering of the constituents. Topicalization often fulfills the need to create a new prosodic domain. This new phrase, analyzed in the present paper as an I-phrase (intonation phrase), presents an alternative to a structure which would otherwise contain two adjacent accents. Moreover, it creates a configuration in which the constituent carrying the topic feature of the sentence may be initial, and thus able to have a rising pitch accent. Similarly, if the focus is final in its I-phrase, it may carry the nuclear falling accent. OT is an excellent framework to deal with this kind of phenomena because it does not pre-empt an organization of grammar in which syntax precedes phonology. On the contrary, it is possible to order syntactic and prosodic constraints so that prosody may influence syntax. In the analysis which has been proposed in this paper, syntactic constraints interact with prosodic ones, and deliver a picture of grammar where placement and shape of pitch accents play a major role for word order.

${ }^{1}$ This paper is part of project A1 of the SFB632 on Information Structure at the University of Potsdam, and of the project on split constructions, both financed by the DFG. Thanks to Shin Ishihara, Werner Frey, Ingo Feldhausen and an anonymous reviewer for detailed comments of a preliminary version. Thanks to Gisbert Fanselow and to Vieri Samek-Lodovici for discussion of some of the issues of this paper. Part of this work has been presented at the ISAG conference. I would like to thank the organizers and the audience of the ISAG conference for their interest. Thanks also to Elizabeth Medvedovsky and Esther Sommerfeld for checking English. All errors and omissions are mine. 
${ }^{2}$ As far as I-phrases are concerned, no unique syntactic construction can be found with which they coincide. For this reason, no constraint similar to STRESSXP is offered here. An I-phrase, like a P-phrase, is uniquely headed.

${ }^{3}$ Another way to explain the accent on $\quad \operatorname{him}$ in (7a) is in terms of nested foci, as in Féry \& Samek-Lodovici (2006). The wh-constituent who triggers an extra-F-mark inside of the VP, and this extra-F-mark renders him more prominent than the verb, see below for the relevant constraint.

${ }^{4}$ See also the so-called Second Occurrence Focus (SOF) sentences, as discussed in Beaver et al. (2004) and in Féry \& Ishihara (2005), which present a slightly different challenge for the theory presented here. SOF is realized with a pitch accent prenuclearly, but is subject to deaccenting postnuclearly.

${ }^{5}$ Frey (2004) also claims that the word order of (20b) can be found in a sentence in which seine Tochter is not contrastive. In this case, scrambling has applied first, and in a second step formal movement. This case is not considered here, but I assume that the prosodic structure of such a sentence is similar to the one of (20a).

${ }^{6}$ Thanks to Shin Ishihara and to the anonymous reviewer for pointing this out.

${ }^{7}$ The anonymous reviewer points out that in a topic prominent language like Romanian, fish in the same context would be topicalized and the negative quantifier could move to the sentenceinitial structural focus position immediately following the topic.

\section{References}

Beaver, D., Clark, B., Flemming, E., Jäger, F. and Wolters, M. 2004. When Semantics Meets Phonetics. Acoustical studies of Second Occurrence Focus. Stanford University. Ms.

Büring, D. 1997. The 49th Bridge Accent. Berlin: Mouton de Gruyter.

Büring, D. 2001. "Let's Phrase it! Focus, Word Order, and Prosodic Phrasing in German Double Object Constructions". In Competition in Syntax, G. Müller and W. Sternefeld (eds), 69-105. New York: Mouton de Gruyter.

Büring, D. 2003a. “On D-Trees, Beans and B-accents”. Linguistics \& Philosophy 26 (5): 511545.

Büring, D. 2003b. Focus Projection and Default Prominence. Ms. University of California, Los Angeles.

Chomsky, N. and Halle, M. 1968. The Sound Pattern of English. New York: Harper and Row.

Cinque, G. 1999. Adverbs and Functional Heads: A Cross-linguistic Perspective. Oxford: Oxford University Press.

De Kuthy, K. 2002. Discontinuous NPs in German. A Case Study of the Interaction of Syntax, Semantics, and Pragmatics. Stanford, California: CSLI Publications.

Elenbaas, N. and Kager, R. 1999. "Ternary rhythm and the lapse constraint”. Phonology 16: 273330.

Fanselow, G. 1987. “Konfigurationalität. Untersuchungen zur Universalgrammatik am Besipiel des Deutschen". Studien zur deutschen Grammatik, Vol. 29. Tübingen: Narr.

Fanselow, G. 2002. "Quirky Subjects and other Specifiers". In More Than Words, I. Kaufmann and B. Stiebels (eds), 227-250. Berlin: Akademie Verlag. 
Fanselow, G. 2004. "Cyclic Phonology-Syntax-Interaction: Movement to First Position in German". In Information Structures 1. Working Papers of the SFB 632, S. Ishihara, M. Schmitz and A. Schwarz (eds), 1-42. Potsdam.

Fanselow, G. and Cavar, D. 2002. "Distributed Deletion". In Theoretical Approaches to Universals, A. Alexiadou (ed.), 65- 107. Amsterdam: Benjamins.

Féry, C. 1993. German intonational patterns. Niemeyer, Tübingen.

Féry, C. and Ishihara, S. 2005. Interpreting Second Occurence Focus. Ms. University of Potsdam.

Féry, C. and Hartmann, K. 2005. "Focus and prosodic structures of German Gapping and Right Node Raising". The Linguistic Review 22: 67-114.

Féry, Caroline \& Alla Paslawska (2005) Discontinuous constructions in Ukrainian. Ms. University of Potsdam and University of Lwiw.

Féry, C. and Samek-Lodovici, V. 2006. Focus Projection and Prosodic Prominence in Nested Foci. Language 82.1.

Frey, Werner. 2004. The grammar-pragmatics interface and the German prefield. Ms. ZAS, Berlin.

Ghini, M. 1993. "Ø-formation in Italian: A new proposal”. In Toronto Working Papers in Linguistics Vol. 12, No. 2, C. Dyck (ed.), 41-78. Department of Linguistics, University of Toronto.

Givón, T. 1990. Syntax: A Functional Typological Introduction. Amsterdam: Benjamins.

Grewendorf, G. and Sabel, J. 1994. "Long scrambling and incorporation". Linguistic Inquiry 25: 263-308.

Gundel, J. 1996. "Relevance Theory Meets the Givenness Hierarchy. An Account of Inferrables". In Reference and Referent Accessibility, T. Fretheim and J. Gundel (eds.), 141153. Amsterdam: John Benjamins.

Gussenhoven, C. 1992. "Sentence accents and argument structure". In Thematic Structure: Its Role in Grammar, I. Roca (ed.), 79-106. Berlin: Foris.

Haider, H. and Rosengren, I. 1998. "Scrambling". Sprache und Pragmatik 49. Lund: Germanistisches Institut.

Hayes, B. 1995. Metrical stress theory: Principles and case studies. Chicago: University of Chicago Press.

Hoof, H. van. 2004. Split Topicalization (Case 101). The SynCom Project.

Jackendoff, R. S. 1972. Semantic interpretation in generative grammar. Cambridge, Mass.: MIT Press.

Jacobs, J. 1997. "I-Topikalisierung“. Linguistische Berichte 168: 91-133.

Jacobs, J. 2001. "The dimensions of topic-comment”. Linguistics 39 (4): 641-681.

Lambrecht, K. 1994. Information Structure and Sentence Form. Cambridge: Cambridge. University Press.

Lenerz, J. 1977. Zur Abfolge nominaler Satzglieder im Deutschen. Tübingen: Narr.

McCarthy, J.J. and Prince, A.S. 1993. "Generalized Alignment”. In Yearbook of Morphology 1993, G. Booij and J. van Marle (eds), 79-153. Dordrecht: Kluwer.

Müller, G. 1998. Incomplete category fronting. Dordrecht. Kluwer.

Müller, G. 2003. "Verb-Second as vP-First". Journal of Comparative Germanic Linguistics 7.3: 179-234. 
Müller, G. and Sternefeld, W. 1993. „Improper movement and unambiguous binding”. Linguistic Inquiry 24: 461-507.

Neeleman, A. and Szendröi, K. 2004. "Superman Sentences”. Linguistic Inquiry 35: 149-159.

Nespor, M. and Vogel, I. 1986. Prosodic Phonology. Dordrecht: Foris.

Prince, A. and Smolensky, P. 1993. Optimality Theory: Constraint Interaction in Generative Grammar. Ms., Rutgers University, New Brunswick, \& University of Colorado, Boulder.

Prince, E.F. 1981. "Toward a Taxonomy of Given-New Information". In Radical Pragmatics, P. Cole (ed.), 223-256. New York: Academic Press.

Reinhart, T. 1981. Pragmatics and linguistics: An analysis of sentence topics. Philosophica 27: 53-94.

Riemsdijk, H. van. 1989 "Movement and Regeneration". In Dialectal Variation and the Theory of Grammar, P. Beninca (ed.), 105-136. Dordrecht: Foris.

Roberts, C. 1996. "Information Structure in Discourse: Towards an Integrated Formal Theory of Pragmatics". In OSU Working Papers in Linguistics 49: Papers in Semantics, J.H. Yoon and A. Kathol (eds.), 91-136.

Rooth, M. 1992. “A Theory of Focus Interpretation". Natural Language Semantics 1: 75-116.

Samek-Lodovici, V. 2005. "Prosody-Syntax Interaction in the Expression of Focus". Natural Language and Linguistic Theory 23.

Schwarzschild, R. 1999. "GIVENness, AVOIDF and Other Constraints on the Placement of Accent”. Natural Language Semantics 7: 141-177.

Selkirk, E. 1984. Phonology and Syntax: The Relation between Sound and Structure. Cambridge, MA: MIT Press.

Selkirk, E. 1995. "Sentence Prosody: Intonation, Stress and Phrasing”. In Handbook of Phonological Theory, J. Goldsmith (ed.), 550-569. Cambridge, MA: Blackwell.

Selkirk, E. 2000. "The Interaction of Constraints on Prosodic Phrasing”. In Prosody: Theory and Experiment, M. Horne (ed.), 231-261. Dordrecht: Kluwer.

Steedman, M. 2000. "Information Structure and the Syntax-Phonology Interface". Linguistic Inquiry 31: 649-689.

Szendröi, K. 2003. "A stress-based approach to the syntax of Hungarian focus". Linguistic Review 20: 37-78

Thiersch, C. 1978. Topics in German Syntax. Dissertation, MIT, Cambridge, Mass.

Truckenbrodt, H. 1995. Phonological Phrases: Their Relation to Syntax, Focus and Prominence. Ph.D dissertation (unpublished), MIT.

Truckenbrodt, H. 1999. "On the Relation between Syntactic Phrases and Phonological Phrases". Linguistic Inquiry 30: 219-255. 